\title{
Improving Diagnostic Workup Following Traumatic Spinal Cord Injury: Advances in Biomarkers
}

\author{
Simon Schading ${ }^{1} \cdot \operatorname{Tim}^{\text {M. Emmenegger }}{ }^{1} \cdot$ Patrick Freund $^{1}$ (D)
}

Accepted: 24 June 2021 / Published online: 16 July 2021

(C) The Author(s) 2021

\begin{abstract}
Purpose of Review Traumatic spinal cord injury (SCI) is a life-changing event with drastic implications for patients due to sensorimotor impairment and autonomous dysfunction. Current clinical evaluations focus on the assessment of injury level and severity using standardized neurological examinations. However, they fail to predict individual trajectories of recovery, which highlights the need for the development of advanced diagnostics. This narrative review identifies recent advances in the search of clinically relevant biomarkers in the field of SCI.

Recent Findings Advanced neuroimaging and molecular biomarkers sensitive to the disease processes initiated by the SCI have been identified. These biomarkers range from advanced neuroimaging techniques, neurophysiological readouts, and molecular biomarkers identifying the concentrations of several proteins in blood and CSF samples. Some of these biomarkers improve current prediction models based on clinical readouts. Validation with larger patient cohorts is warranted.

Summary Several biomarkers have been identified — ranging from imaging to molecular markers — that could serve as advanced diagnostic and hence supplement current clinical assessments.
\end{abstract}

Keywords Spinal cord injury $\cdot$ Biomarker $\cdot$ Severity assessment $\cdot$ Prognostic factors $\cdot$ Pathophysiology $\cdot$ Predictive model

\section{Introduction}

Traumatic spinal cord injury (tSCI) is a devastating event and most often leads to serious sensorimotor deficits and autonomous dysfunctions. The worldwide yearly incidence of SCI is estimated at 40 up to 80 cases per million [1]. While traumatic causes such as road traffic incidents and falls are the predominant etiology in the younger population, non-traumatic causes, including neoplastic tumors and degenerative conditions, increase with age. Currently there is no cure, and functional recovery is limited, leaving the majority of patients with severe and permanent impairments [2]. Accordingly, patients are eager to know their prognosis soon after the injury, as to whether they will regain voluntary control of upper and lower limbs as well as autonomous function [3]. Therefore, advanced diagnostic measures that can increase the accuracy of

Patrick Freund

patrick.freund@balgrist.ch

1 Spinal Cord Injury Centre, Balgrist University Hospital, University of Zurich, Forchstrasse 340, 8008 Zurich, Switzerland prediction models which ultimatively can predict individual trajectories of recovery are required.

Routine clinical evaluations for assessing the current clinical impairment include performing the International Standards for the Neurological Classification of Spinal Cord Injury (ISNCSCI) protocol at admission. Based on this assessment, the patient's overall impairment is classified on the American Spinal Injury Association (ASIA) Impairment scale (AIS) $[4,5]$. This scale represents the gold standard assessment for documentation of the level and severity of a SCI [5]. It classifies patients according to their motor and sensory impairment into five categories (A-E) with category A corresponding to the most severely impaired patients and category E indicating no clinically relevant impairment. A recent review analyzing multiple clinical and demographic factors and their contribution to the prediction of global functional outcome concluded that the severity of SCI measured by the AIS was the strongest predictive factor [6]. However, the major limiting factor for using the AIS scores for prediction is the substantial heterogeneity of individual recovery potentials in each category. This may lead to a diverse range of recovery trajectories between patients with similar initial clinical impairment and result in different long-term functional 
outcomes, which highlights the need for more refined assessments and the incomplete understanding of the exact pathophysiological mechanisms [7, 8]. Moreover, differences in neurological examination timing introduce additional heterogeneity in the classification of patients due to higher variability in spontaneous recovery during the early phase after injury. Therefore, outcome prediction based on neurological assessments performed very early after injury may differ from predictions based on neurological examinations at later stages [9]. Another drawback arises in cases of intoxication, sedation, or patients with concomitant brain injuries, which makes the initial neurological assessment challenging $[10 \bullet, 11]$. Hence, advanced diagnostics which can describe the impact of the trauma independent from the neurological assessment are required. This narrative review critically evaluates the literature from the past 5 years and provides an overview of the developments in identifying biomarkers which can potentially serve as advanced diagnostics in tSCI. We will first provide an overview of current predictive models based on clinical evaluation and then continue describing biomarkers derived from neuroimaging, blood and CSF concentrations of several compounds, and the value of neurophysiologic readouts.

\section{Clinical Outcome Measures}

Trying to predict recovery based on clinical parameters, a prognostic model was formulated including the five variables: age ( $<65$ years vs $\geq 65$ years), L3 and S1 motor, and light touch scores, which were acquired within 15 days post injury. It serves to predict independent walking 1-year post injury [12]. This model was simplified having only the three remaining variables: age ( $<65$ years vs $\geq 65$ years), L3 motor score, and S1 light touch score [13]. Critical analysis of both models with different patient cohorts revealed that these models achieved high prognostic accuracy for combined AIS categories, whereas applying these models to single AIS sub-groups led to considerably lower accuracy, thus limiting their applicability $[14 \bullet, 15]$. Models that include additional parameters or use machine learning algorithms have been developed but showed comparable or inferior predictive accuracy of patient's mobility [16-19].

A recent approach for classifying a patient population into more homogeneous sub-groups is the unbiased recursive partitioning technique called conditional inference tree (URP-CTREE) that defines simple decision rules for partitioning the population [20]. This model was used for sub-classifying cervical sensorimotor complete (AIS A) SCI patients into sub-groups based on clinical parameters obtained within the first 2 weeks after injury [21]. The patients within one of these newly defined sub-groups expressed a more homogeneous recovery pattern. These results suggest that the use of such regression tree algorithms provides an easy method for partitioning a heterogeneous SCI patient population into homogenous sub-groups for improving prognostication $[22,23]$.

\section{Neuroimaging Biomarkers}

Radiologic examinations are an integral part of the diagnostic evaluation following SCI and play an important role in assessing the level and severity of injury. Computed tomography $(\mathrm{CT})$ provides excellent visualization of osseous anatomy and fractures and allows fast image acquisition [24]. However, its lack of soft tissue contrast and the insensitivity for visualization of neural damage might lead to underestimation of canal compromise and misdiagnosis in the clinical setting $[25,26]$. In contrast to $\mathrm{CT}$, conventional magnetic resonance imaging (MRI) helps to evaluate the damage to discoligamentous and neural structures after tSCI. It improves clinical decision-making early after trauma and facilitates finding the appropriate treatment [27]. The following paragraphs discuss both imaging parameters derived from conventional neuroimaging and advanced neuroimaging protocols that provide further insights into microstructural alterations.

\section{Conventional MRI at Lesion Site}

The standard protocol in clinical routine after SCI comprises T1-weighted (T1w) and T2-weighted (T2w) MR images of the lesion level [24]. It serves to rapidly screen patients and represents an important prognostic indicator in the current clinical routine [28]. These sequences allow to measure several lesion characteristics such as maximum canal compromise (MCC), maximum spinal cord compression (MSCC), and intramedullary lesion length (IMLL) (see Fig. 1A-C for illustration). The MCC is calculated as the ratio of the anteroposterior (a-p) diameter of the spinal canal at the level of maximum injury $\left(D_{i}\right)$ to the a-p diameter at the nearest normal levels $\left(D_{a}\right.$ and $\left.D_{b}\right)$ as measured on mid-sagittal T1w images. Similarly, the MSCC is derived as the ratio of the a-p spinal cord diameter at the level of maximum injury $\left(\mathrm{d}_{\mathrm{i}}\right)$ to the a-p diameter at the nearest normal levels $\left(\mathrm{d}_{\mathrm{a}}\right.$ and $\left.\mathrm{d}_{\mathrm{b}}\right)$, measured on mid-sagittal T2w images [26]. Some studies demonstrated high inter- and intra-observer reliability of the MCC and MSCC measurements and correlation with injury severity and neurologic outcome $[25,26]$. However, their predictive value disappeared, when the initial neurological status was available, demonstrating the limits of prognostication based on these measures [30, 31].

The IMLL, measured as the length from the most rostral to the most caudal apices of hyperintensive signal changes within the spinal cord on mid-sagittal T2w images, was found to be a good measure for assessing the severity of SCI and showed 

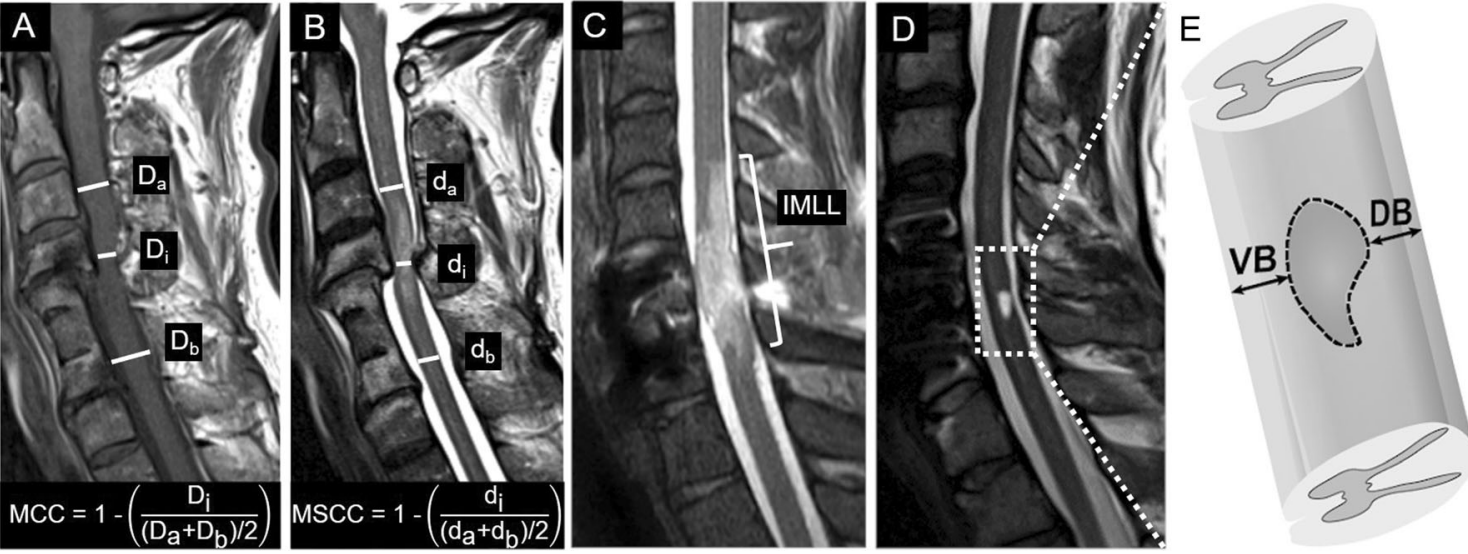

Figure 1. Lesion characteristics derived from standard MRI sequences. A Mid-sagittal T1-weighted MR image with the a-p diameters of the spinal canal at injury site $\left(\mathrm{D}_{\mathrm{i}}\right)$ and at nearest normal levels above $\left(\mathrm{D}_{\mathrm{a}}\right)$ and below $\left(D_{b}\right)$ the lesion, including the equation for MCC. B Mid-sagittal T2weighted MR image with the a-p diameters of spinal cord at maximum injury site $\left(\mathrm{d}_{\mathrm{i}}\right)$ and at nearest normal levels above $\left(\mathrm{d}_{\mathrm{a}}\right)$ and below $\left(\mathrm{d}_{\mathrm{b}}\right)$ the

greater predictive value when compared to MCC and MSCC $[32,33 \bullet \cdot]$. Despite this superiority, its clinical benefit is limited when the initial AIS grade is available, suggesting that the neurological status is more important to predict neurological outcome [31].

An alternative to these measures is the Brain and Spinal Injury Center (BASIC) score, which was proposed to improve the assessment of injury severity prognostication [34]. This classification system qualitatively grades the extent of intramedullary $\mathrm{T} 2 \mathrm{w}$ signal abnormalities in the axial plane on a 5-point classification scheme. It was demonstrated that the BASIC score is a superior predictor of AIS grade compared to MCC, MSCC, and IMLL, and prognostication could be improved by integrating the clinical status and BASIC score $[30,33 \bullet \bullet, 35]$.

Important points to consider when assessing the lesion severity on conventional MR images are the exact anatomical location and local extent of the lesion, as lesions of similar size but different orientations can cause a diverse range and pattern of spared fiber tracts around the lesion [36]. An approach to include information about spared axonal fibers is measuring both ventral and dorsal tissue bridges on a mid-sagittal slice of a T2w image of the spinal cord (see Fig. 1D for illustration). The extent of preserved ventral and dorsal tissue paralleled patients' recovery and electrophysiological recordings in several studies and was significantly related to patients' walking ability [37-39]. Moreover, the width assessed at 1 month after injury was significantly associated with long-term neurological and neurophysiological outcome and could provide a more reliable prognostic measure $[37,38,40 \bullet$, 41]. In particular, the distinction between tract-specific impairment could serve as motor- and sensory-specific predictors separately, as ventral tissue bridges were significantly related to motor function and dorsal tissue bridges to sensory function $[40 \bullet \bullet]$. The lesion, including the equation for MSCC. C IMLL measured on a midsagittal T2-weighted MR image as the rostrocaudal length of the T2w hyperintense lesion. D Mid-sagittal T2-weighted MR image with a T2w hyperintense lesion for the determination of ventral and dorsal tissue bridges as indicated. Modified from Freund et al. [29]

assessment of tract-specific spinal cord damage on axial MRI slices might add valuable prognostic information in the future as well [42].

However, the $\mathrm{T} 2 \mathrm{w}$ signal changes are not specific to the underlying pathophysiology and could represent both transient and irreversible pathologies. Furthermore, there is considerable variation over time and patients, and their quantification relies strongly on the subjective interpretation by the examiner $[29,31]$. This highlights the need for further validation of measures derived from conventional MR imaging in the future in order to evaluate their diagnostic and prognostic value.

\section{Advanced Neuroimaging Markers}

In contrast to conventional MRI sequences, which allow macrostructural assessment of neural tissue damage, new imaging protocols aiming at the quantification of specific tissue parameters serve to assess changes at the microstructural level [43, 44].

A prospective quantitative imaging modality that could serve as diagnostic and prognostic measure after SCI is diffusion tensor imaging (DTI). DTI assesses the microstructural integrity of fiber tracts and, thus, has higher sensitivity to early structural changes $[28,45]$. Measuring spared white matter by means of non-invasive DTI as well as in post-mortem histological samples showed a strong correlation between both measures, pointing at the usefulness of DTI for assessing neuronal tract integrity non-invasively [46]. In both preclinical animal models of SCI and human SCI patients, differences in DTI parameters between SCI and healthy control groups were detected. In particular, SCI patients exhibited increased values of mean diffusivity (MD), indicating disorganization within the fiber tracts and decreased values of fractional anisotropy (FA), representing reduced axonal count and myelin 
content, at the level of injury $[45,47,48]$. Differences in these parameters between healthy controls and SCI patients were also found at levels above and below the lesion [49-51]. Furthermore, several studies showed significant associations between DTI measures and the functional outcome, pointing out the prognostic potential of this imaging technique [ 45 , 48-53]. Contrasting these findings, one recent study comparing DTI and conventional MRI parameters could not prove superiority of DTI measures in predicting neurological outcome, although this study only comprised a small patient cohort [54].

Quantitative parameters for the assessment of microstructural changes are magnetization transfer saturation (MTsat) and longitudinal and effective transverse relaxation rates (R1 $=1 / \mathrm{T} 1, \mathrm{R} 2 *=1 / \mathrm{T} 2 *)$ as implemented in the multi-parameter mapping protocol (MPM) [55]. These quantitative parameters are closely associated with myelin (MTsat, R1) and iron content $(\mathrm{R} 2 *)$ and thereby provide additional pathophysiologic insights into processes following spinal trauma as well as alternative advanced measures for tracking alterations after SCI [56-59]. It could be demonstrated in primates that quantitative MTsat is a robust parameter for tracking demyelination and loss of macromolecules after SCI [60]. Applied to SCI, MPMbased readouts could demonstrate reductions of myelinsensitive parameters and increase in iron content in areas undergoing atrophy [61-64]. This is suggestive of demyelination and iron deposition within these atrophying areas. Changes in myelination and iron deposition were not only restricted to the proximity of the lesion site but also affected remote areas in both the spinal cord and the brain. Moreover, it could be demonstrated that these changes were correlated with longterm neurological outcome, speaking to their potential as new biomarkers for assessing injury severity and predicting outcome in SCI patients [61-63].

In summary, recent developments of MRI sequences allow for the assessment of microstructural neuronal integrity and pathophysiological alterations in myelination and iron deposition and might add valuable information for clinical decision-making and outcome prediction. Future studies are necessary for validating and implementing these methods into clinical practice.

\section{Markers in Cerebrospinal Fluid and Blood Serum}

SCI usually leads to the disruption of the blood spinal cord barrier, resulting in the leakage of several neural tissue components into cerebrospinal fluid (CSF) and blood. Additionally, during the pathophysiological events following SCI, each stage is characterized by up- and downregulations of specific proteins, which renders them an optimal target as biomarker for tracking the stages after SCI [65]. Particularly, assessing the injury severity of unresponsive patients by blood- or CSF-derived markers might facilitate diagnostic workup [66]. Due to the plethora of different compounds, we focus in this review on the most promising factors, whose diagnostic and prognostic usefulness could be replicated (Table 1).

These CSF based biomarkers can broadly be categorized into structural and inflammatory factors, as well as markers measured in routine blood analysis $[85,86]$. Recent research focuses on the usefulness of microRNAs, an abundant class of small non-coding RNAs that were identified as tissue-specific markers of injury. These four classes of biomarkers will be discussed in the subsequent sections.

\section{Structural CSF/Serum Biomarkers}

Structural biomarkers are mostly cell-specific proteins from neuronal tissue that leak into CSF and blood after trauma. These tissue-specific proteins are produced by different cells such as neurons or glia cells. Changes in the blood and CSF concentrations of several of these proteins following SCI were observed and are described in the following section.

Glial fibrillary acidic protein (GFAP) and calcium-binding protein S-100 $\beta$ are mainly derived from glial cells and were repeatedly shown to be elevated in both CSF and blood serum in the early acute phase after SCI in humans and animal models $[10 \bullet, 67-70]$. The levels of both proteins differed significantly between patients with different AIS grades, where most severely affected AIS-A patients expressed the highest measured levels. Additional to the differences between initial AIS categories, patients with lower protein levels exhibited a better neurological recovery than those patients with higher levels. These findings speak to their diagnostic and prognostic potential to assess the severity in the early phase of SCI $[10 \bullet, 67,68,70]$.

Neurofilaments are abundant axonal cytoskeletal proteins that can be divided into three subunits, light (NF-L), middle (NF-M), and heavy chain neurofilament (NF-H), of which NF-L and NF-H have been studied most widely as potential biomarkers in SCI [87]. CSF and serum levels of both NF-H and NF-L were significantly higher in SCI patients compared to controls during the acute phase after SCI $[68,69,71,72]$. However, the discrimination between individual AIS categories was not possible. Regarding the predictive potential, NF$\mathrm{L}$ concentrations correlated with long-term motor outcome, whereas no significant associations between NF-H levels and functional outcome were found [71, 72].

Another protein that is expressed at high levels within neurons is Tau. It has an important function as stabilizer of microtubules and has been studied extensively in the context of Alzheimer's disease due to its involvement in pathogenesis [88]. Increased extracellular levels might be indicative of neuronal damage; thus Tau could serve as a potential biomarker after SCI. In human SCI patients and animal models of SCI, Tau was elevated both in the 
Table 1. Summary of spinal cord injury serum/CSF biomarkers

\begin{tabular}{|c|c|c|c|}
\hline Biomarker & $\begin{array}{l}\text { Pathophysiological } \\
\text { process/origin }\end{array}$ & Main findings and diagnostic/prognostic utility & Reference \\
\hline GFAP & Glial cell injury & $\begin{array}{l}\text { Discrimination between AIS sub-groups by concentrations } \\
\text { during early phase after SCI. Lower levels associated with } \\
\text { better neurological recovery }\end{array}$ & $\begin{array}{l}\text { Dalkilic et al, } 2018 \text { [10•], Kwon et al, } 2017 \text { [67], } \\
\text { Ahadi et al, } 2015 \text { [68], Yang et al, } 2018 \text { [69] }\end{array}$ \\
\hline S-100ß & Glial cell injury & $\begin{array}{l}\text { Discrimination between AIS sub-groups by concentrations } \\
\text { during early phase after SCI. Lower levels associated with } \\
\text { better neurological recovery }\end{array}$ & $\begin{array}{l}\text { Dalkilic et al, } 2018\left[10^{\bullet}\right], \text { Kwon et al, } 2017[67] \\
\text { Du et al, } 2018 \text { [70], Yang et al, } 2018[69]\end{array}$ \\
\hline NF-L, NF-H & Axonal injury & $\begin{array}{l}\text { Higher levels in SCI patients compared to controls during acute } \\
\text { phase. NF-L was correlated with long-term outcome, while } \\
\text { NF-H showed no significant associations }\end{array}$ & $\begin{array}{l}\text { Ahadi et al, } 2015 \text { [68], Yang et al, } 2018 \text { [69], } \\
\text { Kuhle et al, } 2015 \text { [71], Casha et al, } 2018 \text { [72] }\end{array}$ \\
\hline Tau & Neuronal injury & $\begin{array}{l}\text { Elevated levels during acute phase after SCI and discrimination } \\
\text { between AIS sub-groups. Levels correlated with long-term } \\
\text { functional outcome }\end{array}$ & $\begin{array}{l}\text { Dalkilic et al, } 2018 \text { [10•], Kwon et al, } 2017 \text { [67], } \\
\text { Tang et al, } 2019 \text { [73], Caprelli et al, } 2018 \text { [74] }\end{array}$ \\
\hline NSE & $\begin{array}{l}\text { Neuronal cell body } \\
\text { injury }\end{array}$ & $\begin{array}{l}\text { Elevated levels in SCI patients without differences between AIS } \\
\text { sub-groups. Inconsistent findings regarding predictive utility }\end{array}$ & $\begin{array}{l}\text { Ahadi et al, } 2015 \text { [68], Du et al, } 2018 \text { [70], Li } \\
\text { et al, } 2014 \text { [75], de Mello Rieder et al, } 2019 \\
\text { [76] }\end{array}$ \\
\hline IL-6, IL-8 & Inflammation & $\begin{array}{l}\text { Increased levels during acute and subacute phase. Predictive of } \\
\text { AIS conversion in patients }\end{array}$ & $\begin{array}{l}\text { Dalkilic et al, } 2018 \text { [10•], Kwon et al, } 2017 \text { [67], } \\
\text { Yang et al, } 2018 \text { [69], de Mello Rieder et al, } \\
2019 \text { [76] }\end{array}$ \\
\hline MCP-1 & Inflammation & $\begin{array}{l}\text { Elevated early after SCI. Results about prognostic utility are } \\
\text { inconsistent }\end{array}$ & $\begin{array}{l}\text { Dalkilic et al, } 2018 \text { [10•], Kwon et al, } 2017 \text { [67], } \\
\text { Casha et al, } 2018 \text { [72], Heller et al, } 2017 \text { [77] }\end{array}$ \\
\hline Albumin & Hepatic synthesis & $\begin{array}{l}\text { Hypoalbuminemia after SCI was associated with poor long-term } \\
\text { neurological outcome }\end{array}$ & Tong et al, 2018 [78], Vo et al, 2020 [79] \\
\hline microRNAs & Various & $\begin{array}{l}\text { Severity-dependent distinct changes in the expression profile } \\
\text { after SCI with up- and downregulation of certain microRNAs }\end{array}$ & $\begin{array}{l}\text { Sun et al, } 2018 \text { [80], Ding et al, } 2020 \text { [81], Park } \\
\text { et al, } 2019 \text { [82], Li et al, } 2019 \text { [83], } \\
\text { Tigchelaar et al, } 2019 \text { [84] }\end{array}$ \\
\hline
\end{tabular}

Overview of serum/CSF biomarkers with their pathophysiological origin and a short summary of their diagnostic/prognostic utility after SCI

blood and CSF during the acute phase following SCI with the concentration being related to injury severity and allowing to discriminate between AIS categories [10•, 67, 73, 74]. Moreover, the levels correlated with long-term functional outcome pointing at its predictive utility $[10 \bullet, 67]$.

Neuron specific enolase (NSE), an enzyme that is mainly located in neuronal cytoplasm, was identified as a biomarker for neuronal damage in different pathologies [89]. NSE expression in neuronal tissue was shown to be upregulated in SCI models at the injury site [75]. Increased NSE concentrations in the serum were measured in SCI patients during the first days after trauma, although a clear categorization into individual AIS sub-groups was not possible [68, 70, 76]. Regarding its predictive utility, significantly lower concentrations in patients that had a better functional long-term outcome than in patients with only minor functional improvements were found [70]. Contrasting these findings, another study did not detect a strong correlation with long-term functional outcome [76].

\section{Inflammatory CSF/Serum Biomarkers}

Markers of inflammation are upregulated and secreted by various cell types due to the neuro-inflammatory processes elicited by the trauma that may further worsen the injury. Therefore, they do not represent specific predictors of neuronal damage but rather reflect the general inflammatory reaction [85]. This section discusses the potential of some of these inflammatory cytokines as novel diagnostic measures after SCI.

Interleukins (IL) are a large family of cytokines having a diverse range of functions in immune response. Of these, particularly the pro-inflammatory IL- 6 and IL- 8 have been studied in SCI and seem the most promising biomarkers. IL-6 was reported to be elevated during the acute and subacute phase of SCI in a severity-dependent manner $[10 \bullet, 67,76]$. Moreover, patients experiencing AIS improvement had significantly lower levels than patients not improving indicating its usefulness for prognostication $[10 \bullet, 67]$. Likewise, IL-8 was predictive of AIS conversion in the same manner, although IL-6 showed better performance [10•,67].

Monocyte chemoattractant protein-1 (MCP-1) is a chemotactic cytokine (chemokine) produced by various cell types and plays an integral role for immune response [90]. It was found to be elevated in CSF and serum during the early acute phase of SCI and was predictive of neurological recovery [10•, 67, 77]. Contrasting these findings, Casha et al., although measuring an early increase in MCP-1 in CSF after SCI as well, did not detect significant correlations with neurological recovery [72]. 
Similar to structural CSF and serum biomarkers, some markers of inflammation seem to have the potential of improving the assessment of SCI patients. However, it must be noted that these factors only represent the general inflammatory reaction and are not specific to SCI injury.

\section{Markers in Routine Hematology}

Investigating the utility of routinely measured blood parameters such as blood albumin levels for the assessment of injury severity and outcome prediction, it could be shown that hypoalbuminemia was associated with poor long-term neurological outcome and thus could serve as a marker for prognostication $[78,79]$. Additionally, albumin levels measured during the subacute phase were significantly lower in the most severely affected AIS-A patients compared to other AIS groups, pointing at its utility in clinical risk assessment.

Two studies included a plethora of blood parameters measured during the first 2 weeks after SCI into predictive models and tested their contribution to improve the model [91•, 92]. Initial neurological function assessed by clinical evaluation was the most powerful predictor. However, blood measures of liver and kidney function, inflammation, and complete blood count (as marker for blood loss) could add significant prognostic value. These results suggest that prognostication might be improved by including regularly measured blood analytes as surrogates for general body function and secondary organ complications [93-95].

\section{MicroRNAs}

MicroRNAs, a class of short non-coding RNAs, have drawn a particular interest during recent years as they are involved in several regulatory processes including processes after SCI such as regulation of post-injury inflammation, neuroplasticity, and axon and neuron regeneration $[96,97]$. Following SCI, some of these microRNAs are upregulated leading to a decrease in expression of their target genes while others are downregulated. This in turn leads to a change in the microRNA expression profile and thereby to a different measurable spectrum of microRNAs in blood and CSF [80, 81]. This expression profile varies over time after SCI providing the possibility of characterizing each post-injury stage $[82,83]$. A recent study that measured microRNA profiles in CSF and serum of SCI patients showed a severity-dependent expression profile in CSF with AIS-A patients expressing highest concentrations of total microRNAs in CSF shortly after trauma [84]. The extent of upand downregulation of specific microRNAs in CSF varied between different AIS groups as well. Most severely affected patients expressed highest up- and downregulations pointing at the diagnostic utility of microRNAs. Using a distinct set of these up- and downregulated microRNAs, AIS grade improvement could be predicted for patients that were classified as AIS-A at baseline.

\section{Neurophysiologic Markers}

Neurophysiologic techniques, such as measuring nerve conduction, motor-evoked potential (MEP), and somatosensory-evoked potentials (SEP), provide objective measures of neuronal integrity and allow the differentiation between demyelination and axonal damage $[98 \bullet \bullet, 99]$. Their value as independent tool for stratifying SCI patients into sub-groups and their predictive utility were already demonstrated and validated several years ago [99-102]. However, some questioned whether these electrophysiological parameters could add valuable information for improving functional outcome prediction. Hupp et al. could show in a multicenter study that including electrophysiological multimodal parameters into the prediction model leads to better prediction precision of this model, even if the clinical neurological status is available [98・0]. These results suggest that the assessment of neurologic function and prognostic accuracy in SCI patients can be improved by adding neurophysiological methods to standardized clinical evaluation. Nonetheless, this study also identified total motor score as the best single prediction parameter, which once more highlights the importance of clinical evaluation during the diagnostic workup for the assessment of severity in SCI.

\section{Conclusion}

This review described the latest progress in identifying reliable biomarkers for traumatic SCI and improving predictive models. Clinical evaluation by standardized neurological examination constitutes the gold standard for assessing injury severity and predicting functional outcome. Nevertheless, these models can be improved by including advanced diagnostics, suggesting that a multimodal approach — including neuroimaging and CSF/blood markers-improves the accuracy of predicting individual trajectories of recovery. Future studies investigating the exact potential of this approach with multivariate models that can accommodate multimodal data are required for demonstrating the utility of combinations of these advanced biomarkers.

Funding Open Access funding provided by Universität Zürich. This work was supported by Wings for Life, Austria (WFL-CH-007/14). PF is funded by a SNF Eccellenza Professorial Fellowship grant (PCEFP3 $181362 / 1)$. PF has received funding from the European Research Council under the European Union's Seventh Framework Programme 
(FP7/2007-2013) / ERC grant agreement $n^{\circ} 616905$; in the framework of ERA-NET NEURON. and from the European Union's Horizon 2020 research and innovation programme under the grant agreement No 681094 (NISCI).

\section{Compliance with Ethical Standards}

Conflict of Interest Simon Schading, Tim M. Emmenegger, and Patrick Freund declare that they have no conflict of interest.

Human and Animal Rights All reported studies/experiments with human or animal subjects performed by the authors have been previously published and complied with all applicable ethical standards (including the Helsinki declaration and its amendments, institutional/national research committee standards, and international/national/institutional guidelines).

Open Access This article is licensed under a Creative Commons Attribution 4.0 International License, which permits use, sharing, adaptation, distribution and reproduction in any medium or format, as long as you give appropriate credit to the original author(s) and the source, provide a link to the Creative Commons licence, and indicate if changes were made. The images or other third party material in this article are included in the article's Creative Commons licence, unless indicated otherwise in a credit line to the material. If material is not included in the article's Creative Commons licence and your intended use is not permitted by statutory regulation or exceeds the permitted use, you will need to obtain permission directly from the copyright holder. To view a copy of this licence, visit http://creativecommons.org/licenses/by/4.0/.

\section{References}

Papers of particular interest, published recently, have been highlighted as:

- Of importance

•- Of major importance

1. Bickenbach J, Officer A, Shakespeare T, von Groote P, World Health O, The International Spinal Cord S. International perspectives on spinal cord injury / edited by Jerome Bickenbach ... [et al]. Geneva: World Health Organization; 2013.

2. Curt A, Van Hedel HJ, Klaus D, Dietz V. Recovery from a spinal cord injury: significance of compensation, neural plasticity, and repair. J Neurotrauma. 2008;25(6):677-85. https://doi.org/10. 1089/neu.2007.0468.

3. Kirshblum SC, Botticello AL, DeSipio GB, Fichtenbaum J, Shah A, Scelza W. Breaking the news: a pilot study on patient perspectives of discussing prognosis after traumatic spinal cord injury. $\mathrm{J}$ Spinal Cord Med. 2016;39(2):155-61. https://doi.org/10.1179/ 2045772315 y.0000000013.

4. Kirshblum S, Snider B, Rupp R, Read MS. Updates of the International Standards for Neurologic Classification of Spinal Cord Injury: 2015 and 2019. Phys Med Rehabil Clin N Am. 2020;31(3):319-30. https://doi.org/10.1016/j.pmr.2020.03.005.

5. The 2019 revision of the International Standards for Neurological Classification of Spinal Cord Injury (ISNCSCI)-what's new? Spinal Cord. 2019;57(10):815-7. https://doi.org/10.1038/s41393-019-0350-9.

6. Richard-Denis A, Beauséjour M, Thompson C, Nguyen BH, MacThiong JM. Early predictors of global functional outcome after traumatic spinal cord injury: a systematic review. J Neurotrauma. 2018:35(15):1705-25. https://doi.org/10.1089/neu.2017.5403.

7. Marino RJ, Ditunno JF Jr, Donovan WH, Maynard F Jr. Neurologic recovery after traumatic spinal cord injury: data from the Model Spinal Cord Injury Systems. Arch Phys Med Rehabil. 1999;80(11): 1391-6. https://doi.org/10.1016/s0003-9993(99)90249-6.

8. Kramer JLK, Geisler F, Ramer L, Plunet W, Cragg JJ. Open access platforms in spinal cord injury: existing clinical trial data to predict and improve outcomes. Neurorehabil Neural Repair. 2017;31(5): 399-401. https://doi.org/10.1177/1545968316688801.

9. Evaniew N, Sharifi B, Waheed Z, Fallah N, Ailon T, Dea N, et al. The influence of neurological examination timing within hours after acute traumatic spinal cord injuries: an observational study. Spinal Cord. 2020;58(2):247-54. https://doi.org/10.1038/s41393019-0359-0.

10. Dalkilic T, Fallah N, Noonan VK, Salimi Elizei S, Dong K, Belanger L, et al. Predicting injury severity and neurological recovery after acute cervical spinal cord injury: a comparison of cerebrospinal fluid and magnetic resonance imaging biomarkers. J Neurotrauma. 2018;35(3):435-45. https://doi.org/10.1089/neu. 2017.5357 In this study the authors could demonstrate that using combinations of several CSF biomarkers measured during the early phase after SCI allowed the classification of patients into different AIS grades at baseline and the prediction of AIS grade conversion.

11. Snyder R, Verla T, Ropper AE. Practical application of recent advances in diagnostic, prognostic, and therapeutic modalities for spinal cord injury. World Neurosurg. 2020;136:330-6. https://doi.org/10.1016/j.wneu.2020.01.011.

12. van Middendorp JJ, Hosman AJ, Donders AR, Pouw MH, Ditunno JF Jr, Curt A, et al. A clinical prediction rule for ambulation outcomes after traumatic spinal cord injury: a longitudinal cohort study. Lancet. 2011;377(9770):1004-10. https://doi.org/ 10.1016/s0140-6736(10)62276-3.

13. Hicks KE, Zhao Y, Fallah N, Rivers CS, Noonan VK, Plashkes T, et al. A simplified clinical prediction rule for prognosticating independent walking after spinal cord injury: a prospective study from a Canadian multicenter spinal cord injury registry. Spine J. 2017;17(10):1383-92. https://doi.org/10.1016/j.spinee.2017.05. 031.

14. Phan P, Budhram B, Zhang Q, Rivers CS, Noonan VK, Plashkes $\mathrm{T}$, et al. Highlighting discrepancies in walking prediction accuracy for patients with traumatic spinal cord injury: an evaluation of validated prediction models using a Canadian Multicenter Spinal Cord Injury Registry. Spine J. 2019;19(4):703-10. https://doi.org/ 10.1016/j.spinee.2018.08.016 This study re-evaluated previously validated prediction models based on clinical variables and revealed important limitations in their prognostic accuracy.

15. Engel-Haber E, Zeilig G, Haber S, Worobey L, Kirshblum S. The effect of age and injury severity on clinical prediction rules for ambulation among individuals with spinal cord injury. Spine J. 2020;20(10):1666-75. https://doi.org/10.1016/j.spinee.2020.05. 551.

16. Belliveau T, Jette AM, Seetharama S, Axt J, Rosenblum D, Larose $D$, et al. Developing artificial neural network models to predict functioning one year after traumatic spinal cord injury. Arch Phys Med Rehabil. 2016;97(10):1663-8.e3. https://doi.org/10.1016/j. apmr.2016.04.014.

17. DeVries Z, Hoda M, Rivers CS, Maher A, Wai E, Moravek D, et al. Development of an unsupervised machine learning algorithm for the prognostication of walking ability in spinal cord injury patients. Spine J. 2020;20(2):213-24. https://doi.org/10.1016/j. spinee.2019.09.007.

18. Wilson JR, Grossman RG, Frankowski RF, Kiss A, Davis AM, Kulkarni AV, et al. A clinical prediction model for long-term functional outcome after traumatic spinal cord injury based on 
acute clinical and imaging factors. J Neurotrauma. 2012;29(13): 2263-71. https://doi.org/10.1089/neu.2012.2417.

19. Kaminski L, Cordemans V, Cernat E, M'Bra KI, Mac-Thiong JM. Functional outcome prediction after traumatic spinal cord injury based on acute clinical factors. J Neurotrauma. 2017;34(12): 2027-33. https://doi.org/10.1089/neu.2016.4955.

20. Hothorn T, Hornik K, Zeileis A. Unbiased recursive partitioning: a conditional inference framework. J Comput Graph Stat. 2006;15(3):651-74.

21. Tanadini LG, Steeves JD, Hothorn T, Abel R, Maier D, Schubert $\mathrm{M}$, et al. Identifying homogeneous subgroups in neurological disorders: unbiased recursive partitioning in cervical complete spinal cord injury. Neurorehabil Neural Repair. 2014;28(6):507-15. https://doi.org/10.1177/1545968313520413.

22. Buri M, Tanadini LG, Hothorn T, Curt A. Unbiased recursive partitioning enables robust and reliable outcome prediction in acute spinal cord injury. J Neurotrauma. 2021. https://doi.org/10. 1089/neu.2020.7407.

23. Facchinello Y, Beauséjour M, Richard-Denis A, Thompson C, Mac-Thiong JM. The use of regression tree analysis for predicting the functional outcome following traumatic spinal cord injury. J Neurotrauma. 2017;38:1285-91. https://doi.org/10.1089/neu. 2017.5321

24. Shah LM, Ross JS. Imaging of spine trauma. Neurosurgery. 2016;79(5):626-42. https://doi.org/10.1227/neu. 0000000000001336 .

25. Skeers P, Battistuzzo CR, Clark JM, Bernard S, Freeman BJC, Batchelor PE. Acute thoracolumbar spinal cord injury: relationship of cord compression to neurological outcome. J Bone Joint Surg Am. 2018;100(4):305-15. https://doi.org/10.2106/jbjs.16. 00995.

26. Furlan JC, Kailaya-Vasan A, Aarabi B, Fehlings MG. A novel approach to quantitatively assess posttraumatic cervical spinal canal compromise and spinal cord compression: a multicenter responsiveness study. Spine (Phila Pa 1976). 2011;36(10):784-93. https://doi.org/10.1097/BRS.0b013e3181e7be3a.

27. Fehlings MG, Martin AR, Tetreault LA, Aarabi B, Anderson P, Arnold PM, et al. A Clinical practice guideline for the management of patients with acute spinal cord injury: Recommendations on the Role of Baseline Magnetic Resonance Imaging in Clinical Decision Making and Outcome Prediction. Global Spine J. 2017;7(3 Supp1):221s-30s. https://doi.org/10.1177/ 2192568217703089

28. Parthiban J, Zileli M, Sharif SY. Outcomes of spinal cord injury: WFNS spine committee recommendations. Neurospine. 2020;17(4):809-19. https://doi.org/10.14245/ns.2040490.245.

29. Freund P, Seif M, Weiskopf N, Friston K, Fehlings MG, Thompson AJ, et al. MRI in traumatic spinal cord injury: from clinical assessment to neuroimaging biomarkers. The Lancet Neurology. 2019;18(12):1123-35. https://doi.org/10.1016/ s1474-4422(19)30138-3.

30. Mabray MC, Talbott JF, Whetstone WD, Dhall SS, Phillips DB, Pan JZ, et al. Multidimensional analysis of magnetic resonance imaging predicts early impairment in thoracic and thoracolumbar spinal cord injury. J Neurotrauma. 2016;33(10):954-62. https:// doi.org/10.1089/neu.2015.4093.

31. Martineau J, Goulet J, Richard-Denis A, Mac-Thiong JM. The relevance of MRI for predicting neurological recovery following cervical traumatic spinal cord injury. Spinal Cord. 2019;57(10): 866-73. https://doi.org/10.1038/s41393-019-0295-z.

32. Aarabi B, Sansur CA, Ibrahimi DM, Simard JM, Hersh DS, Le E, et al. Intramedullary lesion length on postoperative magnetic resonance imaging is a strong predictor of ASIA impairment scale grade conversion following decompressive surgery in cervical spinal cord injury. Neurosurgery. 2017;80(4):610-20. https://doi. org/10.1093/neuros/nyw053.
33.• Farhadi HF, Kukreja S, Minnema A, Vatti L, Gopinath M, Prevedello L, et al. Impact of admission imaging findings on neurological outcomes in acute cervical traumatic spinal cord injury. J Neurotrauma. 2018;35(12):1398-406. https://doi.org/10. 1089/neu.2017.5510 This study identified the BASIC score as the single best predictor among established measures based on conventional imaging and integration of this scor into prediciton models along with clinical scores led to higher accuracy.

34. Talbott JF, Whetstone WD, Readdy WJ, Ferguson AR, Bresnahan $\mathrm{JC}$, Saigal R, et al. the brain and spinal injury center score: a novel, simple, and reproducible method for assessing the severity of acute cervical spinal cord injury with axial T2-weighted MRI findings. J Neurosurg Spine. 2015;23(4):495-504. https://doi. org/10.3171/2015.1.Spine141033.

35. Haefeli J, Mabray MC, Whetstone WD, Dhall SS, Pan JZ, Upadhyayula P, et al. Multivariate analysis of MRI biomarkers for predicting neurologic impairment in cervical spinal cord injury. Am J Neuroradiol. 2017;38(3):648-55. https://doi.org/10. 3174/ajnr.A5021.

36. Fouad K, Popovich PG, Kopp MA, Schwab JM. The neuroanatomical-functional paradox in spinal cord injury. Nat Rev Neurol. 2021;17(1):53-62. https://doi.org/10.1038/s41582020-00436-x.

37. Pfyffer D, Huber E, Sutter R, Curt A, Freund P. Tissue bridges predict recovery after traumatic and ischemic thoracic spinal cord injury. Neurology. 2019;93(16):e1550-e60. https://doi.org/10. 1212/wnl.0000000000008318.

38. Huber E, Lachappelle P, Sutter R, Curt A, Freund P. Are midsagittal tissue bridges predictive of outcome after cervical spinal cord injury? Ann Neurol. 2017;81(5):740-8. https://doi.org/10.1002/ ana.24932.

39. O'Dell DR, Weber KA, Berliner JC, Elliott JM, Connor JR, Cummins DP, et al. Midsagittal tissue bridges are associated with walking ability in incomplete spinal cord injury: a magnetic resonance imaging case series. J Spinal Cord Med. 2020;43(2):26871. https://doi.org/10.1080/10790268.2018.1527079.

40. Vallotton K, Huber E, Sutter R, Curt A, Hupp M, Freund P. Width and neurophysiologic properties of tissue bridges predict recovery after cervical injury. Neurology. 2019;92(24):e2793-e802. https:// doi.org/10.1212/wnl.0000000000007642.

41.•P Pfyffer D, Vallotton K, Curt A, Freund P. Predictive value of midsagittal tissue bridges on functional recovery after spinal cord injury. Neurorehabil Neural Repair. 2021;35(1):33-43. https:// doi.org/10.1177/1545968320971787 The authors used a URPCTREE algorithm for stratification of SCI patients into more homogeneous recovery subgroups based on the radiologic measure preserved midsagittal tissue bridges and showed that adding this measure into prediction models yielded higher accuracy.

42. Smith AC, Weber KA 2nd, O'Dell DR, Parrish TB, Wasielewski M, Elliott JM. Lateral corticospinal tract damage correlates with motor output in incomplete spinal cord injury. Arch Phys Med Rehabil. 2018;99(4):660-6. https://doi.org/10.1016/j.apmr.2017. 10.002 .

43. Cohen-Adad J. Microstructural imaging in the spinal cord and validation strategies. Neuroimage. 2018;182:169-83. https://doi. org/10.1016/j.neuroimage.2018.04.009.

44. Edwards LJ, Kirilina E, Mohammadi S, Weiskopf N. Microstructural imaging of human neocortex in vivo. Neuroimage. 2018;182:184-206. https://doi.org/10.1016/j. neuroimage.2018.02.055.

45. D'Souza MM, Choudhary A, Poonia M, Kumar P, Khushu S. Diffusion tensor MR imaging in spinal cord injury. Injury. 2017;48(4):880-4. https://doi.org/10.1016/j.injury.2017.02.016. 
46. Song W, Song G, Zhao C, Li X, Pei X, Zhao W, et al. Testing pathological variation of white matter tract in adult rats after severe spinal cord injury with MRI. Biomed Res Int. 2018;2018: 4068156-13. https://doi.org/10.1155/2018/4068156.

47. Seif M, Gandini Wheeler-Kingshott CA, Cohen-Adad J, Flanders AE, Freund P. Guidelines for the conduct of clinical trials in spinal cord injury: neuroimaging biomarkers. Spinal Cord. 2019;57(9): 717-28. https://doi.org/10.1038/s41393-019-0309-x.

48. Zhao C, Rao JS, Pei XJ, Lei JF, Wang ZJ, Zhao W, et al. Diffusion tensor imaging of spinal cord parenchyma lesion in rat with chronic spinal cord injury. Magn Reson Imaging. 2018;47:25-32. https://doi.org/10.1016/j.mri.2017.11.009.

49. David G, Seif M, Huber E, Hupp M, Rosner J, Dietz V, et al. In vivo evidence of remote neural degeneration in the lumbar enlargement after cervical injury. Neurology. 2019;92(12): e1367-e77. https://doi.org/10.1212/wnl.0000000000007137.

50. Shabani S, Kaushal M, Budde M, Kurpad SN. Correlation of magnetic resonance diffusion tensor imaging parameters with American Spinal Injury Association score for prognostication and long-term outcomes. Neurosurg Focus. 2019;46(3):E2. https://doi.org/10.3171/2018.12.Focus18595.

51. Huber E, David G, Thompson AJ, Weiskopf N, Mohammadi S, Freund P. Dorsal and ventral horn atrophy is associated with clinical outcome after spinal cord injury. Neurology. 2018;90(17): e1510-e22. https://doi.org/10.1212/wnl.0000000000005361.

52. Singh R, Magu S, Baskar A, Rohilla RK, Kaur K, Kaur S. Correlation of clinical findings in acute spinal injury patients with magnetic resonance including diffusion tensor imaging and fiber tractography. Spine Surg Relat Res. 2020;4(4):305-13. https:// doi.org/10.22603/ssrr.2020-0048.

53. Shanmuganathan K, Zhuo J, Chen HH, Aarabi B, Adams J, Miller $\mathrm{C}$, et al. Diffusion tensor imaging parameter obtained during acute blunt cervical spinal cord injury in predicting long-term outcome. J Neurotrauma. 2017;34(21):2964-71. https://doi.org/10.1089/ neu.2016.4901.

54. Shanmuganathan K, Zhuo J, Bodanapally UK, Kuladeep S, Aarabi B, Adams J, et al. Comparison of acute diffusion tensor imaging and conventional magnetic resonance parameters in predicting long-term outcome after blunt cervical spinal cord injury. J Neurotrauma. 2020;37(3):458-65. https://doi.org/10.1089/ neu.2019.6394.

55. Weiskopf N, Suckling J, Williams G, Correia M, Inkster B, Tait R, et al. Quantitative multi-parameter mapping of R1, PD*, MT, and R2* at 3T: a multi-center validation. Front Neurosci. 2013;7(95). https://doi.org/10.3389/fnins.2013.00095.

56. Weiskopf N, Lutti A, Helms G, Novak M, Ashburner J, Hutton C. Unified segmentation based correction of R1 brain maps for RF transmit field inhomogeneities (UNICORT). Neuroimage. 2011;54(3):2116-24. https://doi.org/10.1016/j.neuroimage.2010. 10.023 .

57. Langkammer C, Krebs N, Goessler W, Scheurer E, Ebner F, Yen $\mathrm{K}$, et al. Quantitative MR imaging of brain iron: a postmortem validation study. Radiology. 2010;257(2):455-62. https://doi. org/10.1148/radiol.10100495.

58. Schmierer K, Scaravilli F, Altmann DR, Barker GJ, Miller DH. Magnetization transfer ratio and myelin in postmortem multiple sclerosis brain. Ann Neurol. 2004;56(3):407-15. https://doi.org/ 10.1002/ana.20202.

59. Freund P, Weiskopf N, Ashburner J, Wolf K, Sutter R, Altmann $\mathrm{DR}$, et al. MRI investigation of the sensorimotor cortex and the corticospinal tract after acute spinal cord injury: a prospective longitudinal study. The Lancet Neurology. 2013;12(9):873-81. https://doi.org/10.1016/S1474-4422(13)70146-7.

60. Wang F, Li K, Mishra A, Gochberg D, Min Chen L, Gore JC. Longitudinal assessment of spinal cord injuries in nonhuman primates with quantitative magnetization transfer. Magn Reson Med. 2016;75(4):1685-96. https://doi.org/10.1002/mrm.25725.

61. Ziegler G, Grabher P, Thompson A, Altmann D, Hupp M, Ashburner J, et al. Progressive neurodegeneration following spinal cord injury: implications for clinical trials. Neurology. 2018;90(14):e1257-e66. https://doi.org/10.1212/wnl. 0000000000005258 .

62. Seif M, Curt A, Thompson AJ, Grabher P, Weiskopf N, Freund P. Quantitative MRI of rostral spinal cord and brain regions is predictive of functional recovery in acute spinal cord injury. Neuroimage Clin. 2018;20:556-63. https://doi.org/10.1016/j. nicl.2018.08.026.

63. Azzarito M, Seif M, Kyathanahally S, Curt A, Freund P. Tracking the neurodegenerative gradient after spinal cord injury. Neuroimage Clin. 2020;26:102221. https://doi.org/10.1016/j. nicl.2020.102221.

64. Grabher P, Callaghan MF, Ashburner J, Weiskopf N, Thompson AJ, Curt A, et al. Tracking sensory system atrophy and outcome prediction in spinal cord injury. Ann Neurol. 2015;78(5):751-61. https://doi.org/10.1002/ana.24508.

65. Rodrigues LF, Moura-Neto V, TCLS ES. Biomarkers in spinal cord injury: from prognosis to treatment. Mol Neurobiol. 2018;55(8):6436-48. https://doi.org/10.1007/s12035-017-0858y.

66. Leister I, Haider T, Mattiassich G, Kramer JLK, Linde LD, Pajalic A, et al. Biomarkers in traumatic spinal cord injury-technical and clinical considerations: a systematic review. Neurorehabil Neural Repair. 2020;34(2):95-110. https://doi.org/10.1177/ 1545968319899920 .

67. Kwon BK, Streijger F, Fallah N, Noonan VK, Bélanger LM, Ritchie L, et al. Cerebrospinal fluid biomarkers to stratify injury severity and predict outcome in human traumatic spinal cord injury. J Neurotrauma. 2017;34(3):567-80. https://doi.org/10.1089/ neu.2016.4435.

68. Ahadi R, Khodagholi F, Daneshi A, Vafaei A, Mafi AA, Jorjani M. Diagnostic value of serum levels of GFAP, pNF-H, and NSE compared with clinical findings in severity assessment of human traumatic spinal cord injury. Spine (Phila Pa 1976). 2015;40(14): E823-30. https://doi.org/10.1097/brs.0000000000000654.

69. Yang Z, Bramlett HM, Moghieb A, Yu D, Wang P, Lin F, et al. Temporal profile and severity correlation of a panel of rat spinal cord injury protein biomarkers. Mol Neurobiol. 2018;55(3):2174 84. https://doi.org/10.1007/s12035-017-0424-7.

70. Du W, Li H, Sun J, Xia Y, Zhu R, Zhang X, et al. The prognostic value of serum neuron specific enolase (NSE) and S100B level in patients of acute spinal cord injury. Med Sci Monit. 2018;24: 4510-5. https://doi.org/10.12659/msm.907406.

71. Kuhle J, Gaiottino J, Leppert D, Petzold A, Bestwick JP, Malaspina A, et al. Serum neurofilament light chain is a biomarker of human spinal cord injury severity and outcome. J Neurol Neurosurg Psychiatry. 2015;86(3):273-9. https://doi.org/10. 1136/jnnp-2013-307454.

72. Casha S, Rice T, Stirling DP, Silva C, Gnanapavan S, Giovannoni $\mathrm{G}$, et al. Cerebrospinal fluid biomarkers in human spinal cord injury from a phase II minocycline trial. J Neurotrauma. 2018;35(16):1918-28. https://doi.org/10.1089/neu.2018.5899.

73. Tang Y, Liu HL, Min LX, Yuan HS, Guo L, Han PB, et al. Serum and cerebrospinal fluid tau protein level as biomarkers for evaluating acute spinal cord injury severity and motor function outcome. Neural Regen Res. 2019;14(5):896-902. https://doi.org/ 10.4103/1673-5374.249238.

74. Caprelli MT, Mothe AJ, Tator CH. Hyperphosphorylated Tau as a novel biomarker for traumatic axonal injury in the spinal cord. J Neurotrauma. 2018;35(16):1929-41. https://doi.org/10.1089/neu. 2017.5495. 
75. Li M, Wen H, Yan Z, Ding T, Long L, Qin H, et al. Temporalspatial expression of ENOLASE after acute spinal cord injury in adult rats. Neurosci Res. 2014;79:76-82. https://doi.org/10.1016/ j.neures.2013.12.001.

76. de Mello RM, Oses JP, Kutchak FM, Sartor M, Cecchini A, Rodolphi MS, et al. Serum biomarkers and clinical outcomes in traumatic spinal cord injury: prospective cohort study. World Neurosurg. 2019;122:e1028-e36. https://doi.org/10.1016/j.wneu. 2018.10.206.

77. Heller RA, Raven TF, Swing T, Kunzmann K, Daniel V, Haubruck P, et al. CCL-2 as a possible early marker for remission after traumatic spinal cord injury. Spinal Cord. 2017;55(11): 1002-9. https://doi.org/10.1038/sc.2017.69.

78. Tong B, Jutzeler CR, Cragg JJ, Grassner L, Schwab JM, Casha S, et al. Serum albumin predicts long-term neurological outcomes after acute spinal cord injury. Neurorehabil Neural Repair. 2018;32(1):7-17. https://doi.org/10.1177/1545968317746781.

79. Vo AK, Geisler F, Grassner L, Schwab J, Whiteneck G, Jutzeler $\mathrm{C}$, et al. Serum albumin as a predictor of neurological recovery after spinal cord injury: a replication study. Spinal Cord. 2020;59: 282-90. https://doi.org/10.1038/s41393-020-00536-x.

80. Sun P, Liu DZ, Jickling GC, Sharp FR, Yin KJ. MicroRNA-based therapeutics in central nervous system injuries. J Cereb Blood Flow Metab. 2018;38(7):1125-48. https://doi.org/10.1177/ $0271678 \times 18773871$.

81. Ding SQ, Chen YQ, Chen J, Wang SN, Duan FX, Shi YJ, et al. Serum exosomal microRNA transcriptome profiling in subacute spinal cord injured rats. Genomics. 2020;112(2):2092-105. https://doi.org/10.1016/j.ygeno.2019.12.003.

82. Park J, Yi D, Jang J, Hong J. The value of MicroRNAs as an indicator of the severity and the acute phase of spinal cord injury. Ann Rehabil Med. 2019;43(3):328-34. https://doi.org/10.5535/ arm.2019.43.3.328.

83. Li F, Zhou MW. MicroRNAs in contusion spinal cord injury: pathophysiology and clinical utility. Acta Neurol Belg. 2019;119(1):21-7. https://doi.org/10.1007/s13760-019-01076-9.

84. Tigchelaar S, Gupta R, Shannon CP, Streijger F, Sinha S, Flibotte $\mathrm{S}$, et al. MicroRNA biomarkers in cerebrospinal fluid and serum reflect injury severity in human acute traumatic spinal cord injury. J Neurotrauma. 2019;36(15):2358-71. https://doi.org/10.1089/ neu.2018.6256.

85. Albayar AA, Roche A, Swiatkowski P, Antar S, Ouda N, Emara E, et al. Biomarkers in spinal cord injury: prognostic insights and future potentials. Front Neurol. 2019;10:27. https://doi.org/10. 3389/fneur.2019.00027.

86. Yousefifard M, Sarveazad A, Babahajian A, Baikpour M, Shokraneh F, Vaccaro AR, et al. Potential diagnostic and prognostic value of serum and cerebrospinal fluid biomarkers in traumatic spinal cord injury: a systematic review. J Neurochem. 2019;149(3):317-30. https://doi.org/10.1111/jnc.14637.

87. Lee MK, Cleveland DW. Neuronal intermediate filaments. Annu Rev Neurosci. 1996;19:187-217. https://doi.org/10.1146/ annurev.ne.19.030196.001155.

88. Scheltens P, Blennow K, Breteler MM, de Strooper B, Frisoni GB, Salloway S, et al. Alzheimer's disease. Lancet. 2016;388(10043): 505-17. https://doi.org/10.1016/s0140-6736(15)01124-1.

89. Rech TH, Vieira SR, Nagel F, Brauner JS, Scalco R. Serum neuron-specific enolase as early predictor of outcome after inhospital cardiac arrest: a cohort study. Crit Care. 2006;10(5): R133. https://doi.org/10.1186/cc5046.

90. Deshmane SL, Kremlev S, Amini S, Sawaya BE. Monocyte chemoattractant protein-1 (MCP-1): an overview. J Interf Cytokine Res. 2009;29(6):313-26. https://doi.org/10.1089/jir. 2008.0027.
91. Bernardo Harrington GM, Cool P, Hulme C, Osman A, Chowdhury JR, Kumar N, et al. Routinely measured hematological markers can help to predict American Spinal Injury Association Impairment Scale scores after spinal cord injury. J Neurotrauma. 2020. https://doi.org/10.1089/neu.2020.7144 This paper showed that inclusion of routinely measured blood parameters into predictive models for the functional outcome could add prognostic value.

92. Brown SJ, Harrington GMB, Hulme CH, Morris R, Bennett A, Tsang WH, et al. A Preliminary cohort study assessing routine blood analyte levels and neurological outcome after spinal cord injury. J Neurotrauma. 2020;37(3):466-80. https://doi.org/10. 1089/neu.2019.6495.

93. Failli V, Kopp MA, Gericke C, Martus P, Klingbeil S, Brommer $\mathrm{B}$, et al. Functional neurological recovery after spinal cord injury is impaired in patients with infections. Brain $\mathrm{J}$ Neurol. 2012;135(Pt 11):3238-50. https://doi.org/10.1093/brain/aws267.

94. Gallagher MJ, Zoumprouli A, Phang I, Schwab JM, Kopp MA, Liebscher T, et al. Markedly Deranged Injury Site Metabolism and Impaired Functional Recovery in Acute Spinal Cord Injury Patients With Fever. Crit Care Med. 2018;46(7):1150-7. https:// doi.org/10.1097/ccm.0000000000003134.

95. Gris D, Hamilton EF, Weaver LC. The systemic inflammatory response after spinal cord injury damages lungs and kidneys. Exp Neurol. 2008;211(1):259-70. https://doi.org/10.1016/j. expneurol.2008.01.033.

96. Bartel DP. MicroRNAs: genomics, biogenesis, mechanism, and function. Cell. 2004;116(2):281-97. https://doi.org/10.1016/ s0092-8674(04)00045-5.

97. Martirosyan NL, Carotenuto A, Patel AA, Kalani MY, Yagmurlu $\mathrm{K}$, Lemole GM Jr, et al. The role of microRNA markers in the diagnosis, treatment, and outcome prediction of spinal cord injury. Front Surg. 2016;3:56. https://doi.org/10.3389/fsurg.2016.00056.

98.• Hupp M, Pavese C, Bachmann LM, Koller R, Schubert M. Electrophysiological multimodal assessments improve outcome prediction in traumatic cervical spinal cord injury. J Neurotrauma. 2018;35(24):2916-2923. doi: 10.1089/ neu.2017.5576. This paper demonstrated that by integrating neurophysiological parameters and clinical scores these predictive models could be significantly improved and more patients could be correctly classified compared to models based solely on clinical assessments.

99. Hug A, Schuld C, Mürle B, Böttinger M, Weidner N, Rupp R. Ulnar nerve integrity predicts 1-year outcome in cervical spinal cord injury. Neurol Res Pract. 2019;1:11. https://doi.org/10.1186/ s42466-019-0017-1.

100. Curt A, Dietz V. Electrophysiological recordings in patients with spinal cord injury: significance for predicting outcome. Spinal Cord. 1999;37(3):157-65. https://doi.org/10.1038/sj.sc.3100809.

101. Kuhn F, Halder P. Spiess tEMSCISGMR, Schubert M. One-year evolution of ulnar somatosensory potentials after trauma in 365 tetraplegic patients: early prediction of potential upper limb function. J Neurotrauma. 2012;29(10):1829-37. https://doi.org/10. 1089/neu.2011.2277.

102. Petersen JA, Spiess M, Curt A, Dietz V, Schubert M. Spinal cord injury:one-year evolution of motor-evoked potentials and recovery of leg motor function in 255 patients. Neurorehabil Neural Repair. 2012;26(8):939-48. https://doi.org/10.1177/ 1545968312438437.

Publisher's Note Springer Nature remains neutral with regard to jurisdictional claims in published maps and institutional affiliations. 